\title{
Sistem Question Answering untuk Bahasa Bali menggunakan Metode Rule-Based dan String Similarity
}

\author{
Question Answering System for Balinese using Rule-Based and String Similarity \\ Method \\ Made Agus Putra Subali ${ }^{1}$, Puritan Wijaya ${ }^{2}$ \\ ${ }^{1,2}$ Fakultas Informatika dan Komputer, Program Studi Sistem Informasi, \\ Institut Teknologi dan Bisnis STIKOM Bali, Denpasar, Indonesia \\ E-mail: ${ }^{1}$ madeagusputrasubali@gmail.com, ${ }^{2}$ puri@ @stikom-bali.ac.id
}

\begin{abstract}
Abstrak
Sistem question answering merupakan kemampuan sistem untuk memberikan jawaban atas kalimat tanya yang diberikan oleh user. Sampai saat ini penelitian tentang sistem question answering pada bahasa Bali belum pernah dilakukan. Pada penelitian ini kalimat tanya yang digunakan adalah kalimat tanya biasa, sebagai contoh kalimat tanya "akuda memene ngubuh siap?" Dalam bahasa Indonesia "berapa ibumu memelihara ayam?" Data yang digunakan dalam penelitian ini merupakan lima puluh dokumen berbahasa Bali. Sedangkan pada tahap pengujian dilakukan dengan menggunakan dua puluh kalimat tanya. Adapun metode yang diusulkan dalam penelitian ini dimulai dari memberi input pertanyaan, mencari dokumen paling relevan berdasarkan pertanyaan yang diberikan, dan memperoleh jawaban berdasarkan rules untuk setiap pertanyaan. Berdasarkan pengujian pada kedua puluh pertanyaan yang diberikan metode yang diusulkan memperoleh akurasi sebesar $40 \%$ terkait kebenaran respons atau jawaban yang diberikan.
\end{abstract}

Kata kunci: Sistem Question Answering, Rule-Based, Cosine Similarity, N-Gram Similarity

\begin{abstract}
The question answering system is the system's ability to answer the question given by the user. Currently, research on the question answering system in Balinese has never been conducting. In this study, the sentence used is the usual interrogative sentence in Balinese, for example, "akuda memene ngubuh siap?" In Indonesian "berapa ibumu memelihara ayam?" The data have obtained from 50 documents in the Balinese. The testing phase has carried out using 20 interrogative sentences. The proposed method in this study begins with providing the input questions, searching for the most relevant documents, and getting the answers. Based on the testing result's obtained an accuracy of $40 \%$ of the 20 questions given.
\end{abstract}

Keywords: Question Answering System, Rule-Based, Cosine Similarity, N-Gram Similarity

\section{PENDAHULUAN}

Sistem question answering merupakan kemampuan sistem untuk memberikan jawaban atas kalimat tanya yang diberikan oleh user [1]. Kalimat tanya dalam bahasa Bali dapat dibedakan menurut jawaban yang diinginkan dan menurut cakupan isi atau penekanannya [2]. Metode pada sistem question answering memiliki tiga komponen utama yaitu question analysis, passage retrieval, dan answer extraction [3]. Penelitian tentang sistem question answering pernah dilakukan oleh Yusliani [4] menggunakan tipe pertanyaan non-factoid (definisi, alasan, dan metode), dimana pada tahap pengambil dokumen dilakukan proses pencarian lima belas dokumen paling relevan menggunakan persamaan cosinus tertinggi. Untuk memperoleh jawaban terbaik dilakukan dengan mencocokkan dengan rules kalimat yang telah ditetapkan, hasil dari penelitian tersebut memperoleh rerata akurasi $76 \%$ untuk pertanyaan definisi, $59 \%$ 
untuk pertanyaan alasan, dan $57 \%$ untuk pertanyaan metode. Sedangkan, penelitian yang dilakukan oleh Purwarianti [5] menggunakan tipe pertanyaan factoid [6], [7] dengan metode atau kerangka sistem question answering yang sama dengan penelitian [4] hasil dari penelitian tersebut memperoleh rerata akurasi 51\%. Baik penelitian [4], [5], [7] bahasa yang digunakan adalah bahasa Indonesia sehingga rules kalimat untuk memperoleh jawaban terbaik tidak cocok dengan bahasa Bali, hasil dari penelitian sistem question answering terdahulu memberikan akurasi yang cukup baik terutama pada pertanyaan definisi. Penelitian lain yang serupa dengan topik sistem question answering yaitu chat bot pernah dilakukan oleh [8] dengan menggunakan line bot application dalam pembuatan kamus penerjemah dari bahasa Indonesia ke bahasa Bali, namun pada penelitian tersebut metode chat bot yang diterapkan sangat sederhana, input hanya menggunakan kata tunggal sekaligus sebagai kata kunci, kemudian respons yang diberikan adalah kata terjemahan yang paling sesuai dengan kata kunci, apabila kata kunci tidak ditemukan maka tidak ada hasil yang diberikan. Sampai saat ini penelitian tentang sistem question answering pada bahasa Bali belum pernah dilakukan.

Pada sistem question answering selain menerima kata kunci input, dilakukan tahap pengambilan dokumen yang paling relevan berdasarkan kata kunci, serta tahapan pencarian jawaban diperoleh berdasarkan rules di setiap kata tanya pada kata kunci. Pembentukan rules dibentuk berdasarkan kata tanya yang digunakan. Kalimat tanya dalam Bahasa Bali, dibedakan menjadi dua bentuk yaitu kalimat tanya biasa dan kalimat tanya retoris. Kalimat tanya biasa adalah kalimat tanya yang meminta jawaban sesuai dengan pertanyaan, sedangkan kalimat tanya retoris adalah kalimat tanya yang tidak memerlukan jawaban karena penanya sudah mengetahui jawabannya [2]. Pada penelitian ini kalimat tanya yang akan digunakan adalah kalimat tanya biasa, seperti akuda, apa, dija, kenken, kuda, dan nyen, sebagai contoh kalimat tanya "akuda memene ngubuh siap?" memiliki arti "berapa ibumu memelihara ayam?"

Data yang digunakan dalam penelitian ini merupakan lima puluh dokumen berbahasa Bali dari buku pelajaran sekolah dasar, sedangkan pada tahap pengujian dilakukan dengan menggunakan dua puluh kalimat tanya dengan variasi tipe pertanyaan definisi dalam bahasa Bali. Adapun metode yang diusulkan dalam penelitian ini dimulai dari (a) memberi input pertanyaan, (b) mencari sepuluh dokumen paling relevan berdasarkan pertanyaan yang diberikan dengan memperhatikan nilai kesamaan cosinus tertinggi menggunakan metode cosine similarity, serta $(c)$ memperoleh jawaban berdasarkan rules untuk setiap pertanyaan, rules untuk setiap pertanyaan ditentukan berdasarkan keputusan expert. Hasil yang diperoleh dalam penelitian ini adalah sistem question answering yang diusulkan mampu merespons jawaban dengan akurasi kebenaran sebesar $40 \%$.

\section{METODE PENELITIAN}

Pada Gambar 1 merupakan metode usulan yang terdiri dari beberapa tahapan, antara lain: input pertanyaan, data preprocessing, analisis pertanyaan, ambil dokumen, cari jawaban, dan output jawaban.

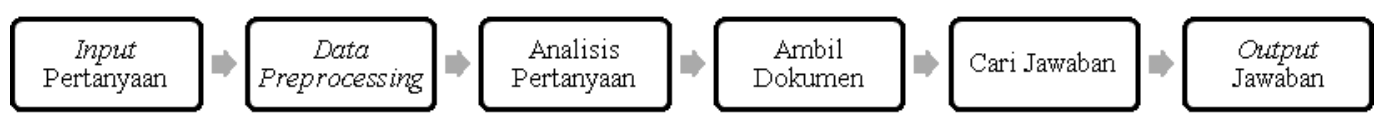

Gambar 1 Metode Usulan

\subsection{Input Pertanyaan}

Pertanyaan yang dimasukkan adalah kalimat tanya bertipe definisi dalam bahasa Bali, seperti kata: akuda, apa, dija, kenken, kuda, dan nyen [2].

\subsection{Data Preprocessing}

Adapun tahapan data pre-processing yang dilakukan adalah tokenize, hapus stop word dengan menghilangkan kata seperti anggen, sane, ring, miwah, puniki, olih, [9] serta tambahan 
kata di dan $i$, kemudian stemming bahasa Bali menggunakan [10] dari input pertanyaan.

\subsection{Analisis Pertanyaan}

Analisis pertanyaan digunakan untuk memperoleh kata kunci dari tahap data preprocessing, kata kunci yang dimaksud adalah kata benda, kata kerja, dan kata tanya [4], [5].

\subsection{Ambil Dokumen}

Tahap ambil dokumen digunakan untuk mengambil sepuluh dokumen paling relevan dari lima puluh dokumen, dengan cara mengukur tingkat kemiripan setiap dokumen dengan kata kunci yang diperoleh menggunakan metode cosine similarity [11], seperti pada persamaan (1).

$$
\operatorname{similarity}\left(d_{j}, q\right)=\frac{d_{j} \cdot q}{\left|d_{j}\right| \cdot|q|}=\frac{\sum_{i=1}^{n}\left(W_{i, j} \cdot W_{i, q}\right)}{\sqrt{\sum_{i=1}^{n} W_{i, j}^{2} \cdot \sum_{i=1}^{n} W_{i, q}^{2}}}(1)
$$

Keterangan:

$W_{i, j}$ merupakan bobot kata $i$ pada dokumen $j$.

$W_{i, q}$ merupakan bobot kata $i$ pada pertanyaan $q$.

Untuk memperoleh bobot kata dihitung menggunakan $t f \cdot i d f$ kata tersebut.

\subsection{Cari Jawaban}

Tahap cari jawaban digunakan untuk memperoleh jawaban terbaik berdasarkan dokumen yang diperoleh pada tahap ambil dokumen. Dokumen paling relevan dari lima puluh dokumen akan diukur tingkat kemiripannya dengan rules atau aturan pencari jawaban dengan menggunakan kombinasi persamaan (2) dan persamaan (3). Penggunaan persamaan (3) digunakan untuk mengukur tingkat kemiripan struktur kalimat pada dokumen dengan rules pencari jawaban [12]. Adapun beberpa rules yang diusulkan terlihat pada Tabel 1.

$$
\text { IF } p \text { THEN } q \text { (2) }
$$

Keterangan:

IF menerangkan suatu kondisi $p$.

THEN menerangkan aksi $q$.

$$
d c=(2 \cdot c) \div(a+b)(3)
$$

Keterangan:

$d c$ merupakan hasil perhitungan tingkat kemiripan.

$a$ merupakan bentuk $n$-gram pada kata pertama.

$b$ merupakan bentuk $n$-gram pada kata kedua.

$c$ merupakan bentuk $n$-gram yang sama antara $a$ dan $b$.

Tabel 1 Rules Pencari Jawaban Bahasa Bali

\begin{tabular}{|c|c|}
\hline Tipe Pertanyaan & Rule Pencari Jawaban \\
\hline Akuda & Kata Kunci + Sufiks -Ne + Kata Khusus (Ada) + Jawaban. \\
\hline Apa & $\begin{array}{r}\text { Kata Khusus (Sawireh) + Kata Kunci + Jawaban. } \\
\text { Kata Kunci + Kata Khusus (Saja Mirib) + Jawaban. }\end{array}$ \\
\hline Dija & $\begin{array}{r}\text { Kata Khusus (Awake) + Kata Kunci +Jawaban. } \\
\text { Jawaban + Kata Khusus (Ada) + Kata Kunci. }\end{array}$ \\
\hline Kenken & $\begin{array}{r}\text { Kata Kunci + Jawaban. } \\
\text { Kata Kunci + Kata Kunci + Prefiks -Ma + Jawaban. } \\
\text { Kata Khusus (Makejang) + Kata Kunci + Jawaban. }\end{array}$ \\
\hline Kuda/Kudang & $\begin{array}{r}\text { Kata Khusus (Ada) + Jawaban + Kata Kunci. } \\
\text { Kata Khusus (Ada) + Jawaban. }\end{array}$ \\
\hline Nyen & $\begin{array}{r}\text { Jawaban + Kata Kunci. } \\
\text { Kata Kunci + Jawaban + Kata Kunci. }\end{array}$ \\
\hline
\end{tabular}

\subsection{Output Jawaban}

Satu jawaban terbaik yang diperoleh dari dokumen paling relevan dari lima puluh dokumen yang digunakan akan ditampilkan. 


\section{HASIL DAN PEMBAHASAN}

\subsection{Dataset}

Data penelitian yang digunakan dalam penelitian ini adalah 50 dokumen berbahasa Bali. Pada setiap dokumen berisi informasi yang berkorelasi dengan setiap topik dokumen. Seluruh dokumen diperoleh dari buku mata pelajaran sekolah dasar. Sedangkan dalam tahap pengujian digunakan 20 pertanyaan beserta jawabannya sebagai acuan dalam menentukan hasil penelitian. Pada Tabel 2 merupakan kedua puluh pertanyaan.

Tabel 2 Kedua Puluh Pertanyaan

\begin{tabular}{|c|c|}
\hline No. & Pertanyaan \\
\hline 1 & dadong dauh ngelah siap mabulu mawarna kenken? \\
\hline 2 & kuda siap putihe mataluh? \\
\hline 3 & nyen sane ngelah siap putih? \\
\hline 4 & apa krana i kekua berang aking? \\
\hline 5 & dija i lutung nepukin tongos melah? \\
\hline 6 & i kancil dadi juru kemit apa? \\
\hline 7 & dugas i malu nyen sane matanduk? \\
\hline 8 & kenken warnan bok i kaki? \\
\hline 9 & akuda made santi ngelah kreta? \\
\hline 10 & kenkenang patutne plaliane suud anggo? \\
\hline 11 & dija i wayan susila malajah ngigel? \\
\hline 12 & anak sane kenken madan ubuh? \\
\hline 13 & jam kuda murid kelas duane masuk? \\
\hline 14 & kudang wuku muride maan libur? \\
\hline 15 & kali kenken i siap selem makeber? \\
\hline 16 & nyen dadi ketua kelas di kelas dua? \\
\hline 17 & nyen adan guru kelas duane? \\
\hline 18 & makire kija putri meseh penganggo? \\
\hline 19 & nyen ane teka tur nyaplok batu? $?$ \\
\hline 20 &
\end{tabular}

\subsection{Analisis Pertanyaan}

Berdasarkan kedua puluh input pertanyaan yang diberikan tahap analisis pertanyaan mampu membedakan kata kunci berupa kata tanya dan kata kunci lain. Pada Tabel 3 merupakan detail kata kunci yang diperoleh dari kedua puluh dokumen. Pada kolom pertanyaan merupakan nomor pertanyaan sesuai pada Tabel 2, kolom kata tanya merupakan kata tanya pada setiap input pertanyaan, kolom kata kunci lain merupakan kata kunci yang bukan merupakan kata tanya dan bukan kata pada daftar stop word.

Tabel 3 Detail Kata Kunci Kedua Puluh Pertanyaan

\begin{tabular}{|c|c|c|c|c|}
\hline No. & Pertanyaan & Kata Tanya & Kata Kunci Lain & Stop Word \\
\hline 1 & $(1)$ & kenken & dadong, dauh, ngelah, siap, mabulu, mawarna & - \\
\hline 2 & (2) & kuda & siap, putihe, mataluh & - \\
\hline 3 & (3) & nyen & ngelah, siap, putih & sane \\
\hline 4 & (4) & apa & krana, kekua, berang, aking & $i$ \\
\hline 5 & (5) & dija & lutung, nepukin, tongos, melah & $i$ \\
\hline 6 & (6) & apa & kancil, dadi, juru, kemit & $i$ \\
\hline 7 & (7) & nyen & dugas, malu, matanduk & sane, $i$ \\
\hline 8 & $(8)$ & kenken & warnan, bok, kaki & $i$ \\
\hline 9 & $(9)$ & $a k u d a$ & made, santi, ngelah, kreta & - \\
\hline 10 & $(10)$ & kenkenang & patutne, plaliane, suud, anggo & - \\
\hline 11 & $(11)$ & dija & wayan, susila, malajah, ngigel & $i$ \\
\hline 12 & (12) & kenken & anak, madan, ubuh & sane \\
\hline
\end{tabular}




\begin{tabular}{|c|c|c|c|c|}
\hline 13 & $(13)$ & kuda & jam, murid, kelas, duane, masuk & - \\
\hline 14 & $(14)$ & kudang & wuku, muride, maan, libur & - \\
\hline 15 & $(15)$ & kenken & kali, siap, selem, makeber & $i$ \\
\hline 16 & $(16)$ & nyen & dadi, ketua, kelas, kelas, dua & $d i$ \\
\hline 17 & $(17)$ & nyen & adan, guru, kelas, duane & - \\
\hline 18 & $(18)$ & kija & makire, putri, meseh, penganggo & - \\
\hline 19 & $(19)$ & nyen & ane, teka, tur, nyaplok, batu & - \\
\hline 20 & $(20)$ & dija & dija, doglagan, medem & $i$ \\
\hline
\end{tabular}

\subsection{Ambil Dokumen}

Pada Tabel 4 merupakan dokumen paling relevan dari kelima puluh dokumen untuk setiap input pertanyaan. Pada kolom pertanyaan merupakan nomor pertanyaan dari input pertanyaan sesuai pada Tabel 2, kolom dokumen (skor) merupakan nomor dokumen sesuai dengan dataset, sedangkan skor atau tingkat kemiripan dari dokumen tersebut dengan kata kunci dari input pertanyaan menggunakan persamaan (1).

Tabel 4 Dokumen Paling Relevan pada setiap Input Pertanyaan

\begin{tabular}{|c|c|c|}
\hline No. & Pertanyaan & Dokumen (Skor) \\
\hline 1 & (1) & $\begin{array}{c}\mathbf{0}(\mathbf{0 . 3 9}) ; \\
1(0.04) ; \\
10(0.07) \\
19(0.13) \\
23(0.06)\end{array}$ \\
\hline 2 & (2) & $0(0.31)$ \\
\hline 3 & (3) & $\begin{array}{c}\mathbf{0}(\mathbf{0 . 2 6}) ; \\
4(0.10) \\
10(0.07) \\
13(0.12) ; \\
19(0.10) \\
22(0.07) ; \\
23(0.06) ;\end{array}$ \\
\hline 4 & (4) & $\begin{array}{l}1(\mathbf{0 . 2 3}) \\
2(0.04) \\
9(0.03)\end{array}$ \\
\hline 5 & (5) & $\begin{array}{c}0(0.10) ; \\
1(\mathbf{0 . 3 3}) ; \\
2(0.13) ; \\
10(0.10) ; \\
18(0.10) ; \\
25(0.10) ; \\
\end{array}$ \\
\hline 6 & (6) & $\begin{array}{c}2(\mathbf{0 . 3 9}) ; \\
14(0.03) ; \\
24(0.03) ;\end{array}$ \\
\hline 7 & (7) & $\begin{array}{c}3(\mathbf{0 . 2 0}) ; \\
13(0.11) ; \\
14(0.04) ;\end{array}$ \\
\hline 8 & (8) & $4(0,31)$ \\
\hline 9 & (9) & $\begin{array}{c}0(0.12) ; \\
10(0.12) ; \\
12(0.05) ; \\
14(0.11) ; \\
17(0.06) ; \\
19(0.17) ; \\
23(0.31) ;\end{array}$ \\
\hline 10 & (10) & $\begin{array}{l}1(0.03) ; \\
11(0.04) ; \\
14(0.09) ; \\
15(0.06) ; \\
18(\mathbf{0 . 1 0}) ; \\
20(0.08) ;\end{array}$ \\
\hline 11 & (11) & $\begin{array}{c}8(0.11) ; \\
11(0.08) ; \\
14(0.06) ; \\
25(\mathbf{0 . 1 3}) ;\end{array}$ \\
\hline 12 & (12) & $\begin{array}{l}0(0.16) \\
9(0.11)\end{array}$ \\
\hline
\end{tabular}




\begin{tabular}{|c|c|c|}
\hline & & $\begin{array}{l}10(0.17) ; \\
16(\mathbf{0 . 1 8}) ;\end{array}$ \\
\hline 13 & (13) & $\begin{array}{l}12 \text { (0.24); } \\
14 \text { (0.04); } \\
16(0.07) ; \\
20(0.11) ; \\
23(0.14) ; \\
25(0.04) ;\end{array}$ \\
\hline 14 & (14) & $\begin{array}{c}9(0.06) \text {; } \\
11(\mathbf{0 . 2 6}) \text {; } \\
12(0.09)\end{array}$ \\
\hline 15 & (15) & $\begin{array}{c}0(0.22) \text {; } \\
29(0.27) \text {; }\end{array}$ \\
\hline 16 & (16) & $\begin{array}{c}2(0.02) ; \\
12(0.25) ; \\
13(0.09) ; \\
14(0.10) ; \\
23(0.19) ; \\
24(0.02) ;\end{array}$ \\
\hline 17 & (17) & $\begin{array}{l}11(0.05) ; \\
12 \text { (0.15); } \\
13(0.13) ; \\
14(0.05) ; \\
23(0.08) ; \\
24(0.05) ;\end{array}$ \\
\hline 18 & (18) & $\begin{array}{c}6(0.17) \text {; } \\
14(0.17) \text {; }\end{array}$ \\
\hline 19 & (19) & $\begin{array}{l}2(0.03) ; \\
8(0.07) ; \\
9(0.04) ; \\
13(0.12) ; \\
16(\mathbf{0 . 1 5}) ; \\
19(0.11) ; \\
21(0.05) ; \\
23(0.06) ; \\
24(0.09) ; \\
28(0.02) ;\end{array}$ \\
\hline 20 & (20) & $29(0.28)$ \\
\hline
\end{tabular}

\subsection{Cari Jawaban}

Pada Tabel 5 merupakan hasil dari proses pencarian jawaban pada setiap input pertanyaan di setiap dokumen paling relevan. Pada kolom pertanyaan merupakan nomor pertanyaan dari input pertanyaan sesuai pada Tabel 2, kolom jawaban merupakan jawaban yang diperoleh dari metode yang diusulkan. Terdapat sembilan pertanyaan yang direspons sedangkan sebelas pertanyaan yang tidak dapat direspons oleh metode yang diusulkan.

Sebagai contoh berikut merupakan tahapan proses dalam mencari jawaban pada baris nomor dua dengan jawaban "ada limolas taluh" pada Tabel 5:

1. Pada tahap analisis pertanyaan diperoleh kata kunci "siap, putihe, mataluh" dan kata tanya "kuda" dari input pertanyaan "kuda siap putihe mataluh?".

2. Berdasarkan rules pencari jawaban pada tipe pertanyaan "kuda/kudang" pada Tabel 1 diperoleh rules sebagai berikut: ada \{jawaban\} 〈katakunci〉. Berdasarkan rules tersebut diperoleh struktur kandidat jawaban sesuai dengan kata kuncinya sebagai berikut:
a. ada \{jawaban\} siap.
b. ada jawaban\} putih.
c. ada jawaban\} taluh.

3. Struktur kandidat jawaban yang diperoleh kemudian diukur tingkat kemiripannya dengan struktur kalimat pada dokumen yang paling relevan. Untuk memperoleh struktur kalimat yang akan diukur dilakukan dengan mengambil tiga kata dengan struktur: ada \{jawaban\} 〈kata kunci〉 dari dokumen, sebagai berikut: "dadong dauh ngelah siap putih suba mataluh reko minab ada limolas taluhne nanging lacur ada nak nepukin anak cerik-cerik kaliwat rusit ipun", terdapat dua kalimat yang mengandung kata khusus "ada" 
yang telah ditandai dengan garis bawah. Pada proses untuk mengukur tingkat kemiripannya dilakukan menggunakan persamaan (3). Berikut adalah hasil dari proses perhitungan:

a. ada limolas taluhne : ada limolas siap $=0.67$

b. ada limolas taluhne $:$ ada limolas putih $=0.65$

c. ada limolas taluhne: ada limolas taluh $=0.94$

d. ada nak nepukin: ada nak siap $=0.56$

e. ada nak nepukin: ada nak putih $=0.62$

f. ada nak nepukin: ada nak taluh $=0.54$

4. Berdasarkan hasil perhitungan tingkat kemiripan dengan skor tertinggi diperoleh kandidat jawaban "ada limolas taluh" dengan skor 0.94 .

Tabel 5 Hasil Pencarian Jawaban pada setiap Input Pertanyaan

\begin{tabular}{|c|c|c|}
\hline No. & Pertanyaan & Jawaban \\
\hline 1 & $(1)$ & - \\
\hline 2 & $(2)$ & ada limolas taluh \\
\hline 3 & $(3)$ & - \\
\hline 4 & $(4)$ & aking saja mirib tuna \\
\hline 5 & $(5)$ & tukad ada tongos \\
\hline 6 & $(6)$ & sawireh dadi juru \\
\hline 7 & $(7)$ & - \\
\hline 8 & $(8)$ & kaki mabok putih \\
\hline 9 & $(9)$ & kretane ada dadua \\
\hline 10 & $(10)$ & - \\
\hline 11 & $(11)$ & - \\
\hline 12 & $(12)$ & - \\
\hline 13 & $(13)$ & - \\
\hline 14 & $(14)$ & ada duang wuku \\
\hline 15 & $(15)$ & selem makeber petenge \\
\hline 16 & $(16)$ & - \\
\hline 17 & $(17)$ & - \\
\hline 18 & $(18)$ & - \\
\hline 19 & $(19)$ & - \\
\hline 20 & $(20)$ & awake medem duur \\
\hline & & \\
\hline
\end{tabular}

\subsection{Evaluasi Hasil}

Berdasarkan kesembilan pertanyaan yang telah diberikan respons, kemudian dilakukan evaluasi apakah respons atau jawaban yang diberikan sudah sesuai atau belum. Evaluasi dilakukan oleh expert dalam bidang ilmu Bahasa Bali. Pada pertanyaan nomor enam respons yang diberikan dianggap salah, sehingga hasil akurasi kesesuaian respons yang diberikan sebesar 40\% diperoleh dari persamaan (4) untuk mengukur akurasi [13].

Rendahnya akurasi yang diperoleh disebabkan adanya beberapa pertanyaan yang tidak dapat memberikan respons, hal ini dikarenakan rules pada pencari jawaban tidak menemukan kecocokan dengan struktur kata pada kalimat atau isi dokumen, seperti sulitnya menemukan jawaban yang berupa frasa, tidak adanya kata khusus pada rules pencari jawaban, dan tidak adanya rules untuk menangani struktur kalimat pasif.

Sebagai contoh pada pertanyaan "dadong dauh ngelah siap mabulu mawarna kenken?" ketiga rules pencari jawaban pada tipe pertanyaan kenken tidak ada yang sesuai dengan struktur kata pada isi dokumen "dadong dauh ngelah siap putih suba mataluh reko minab ada limolas taluhne nanging lacur ada nak nepukin anak cerik-cerik kaliwat rusit ipun...". Pada pertanyaan dan isi dokumen tersebut terdapat kata kunci yang sama yaitu dadong, dauh, ngelah, siap namun pada isi dokumen tidak ditemukan prefiks ma dimana jawaban terdapat setelah kata dengan prefiks ma yaitu putih. Apabila susunan isi dokumen seperti “...ngelah siap mabulu putih..." atau "...ngelah siap mawarna putih" pertanyaan akan direspons dengan benar. 


$$
s=\frac{t}{n} \times 100
$$

Keterangan:

$s$ merupakan hasil perhitungan akurasi.

$t$ merupakan total respons yang sesuai dari keseluruhan pertanyaan.

$n$ merupakan total pertanyaan.

\section{KESIMPULAN DAN SARAN}

Sistem question answering yang diusulkan telah mampu merespons pertanyaan yang diberikan. Berdasarkan kedua puluh pertanyaan, metode yang diusulkan mampu memperoleh akurasi sebesar $40 \%$ atau metode yang diusulkan dapat merespons sembilan pertanyaan dan delapan diantaranya memberikan respons yang sesuai dengan penilaian expert. Pada rules pencari jawaban yang diusulkan belum dapat mencari atau menangani struktur kata yang lebih kompleks seperti jawaban yang berupa frasa ataupun jawaban yang berada pada struktur kalimat pasif. Pada penelitian selanjutnya hasil akurasi akan ditingkatkan dengan membentuk rules yang dapat menangani struktur bahasa yang lebih kompleks serta memperhatikan tanda baca pada isi dokumen untuk mencari jawaban yang berupa frasa.

\section{UCAPAN TERIMA KASIH}

Penulis mengucapkan terima kasih kepada Institut Teknologi dan Bisnis STIKOM Bali yang telah memberi dukungan finansial terhadap penelitian ini.

\section{DAFTAR PUSTAKA}

[1] S. Nalawade, S. Kumar, and D. Tiwari, "Question Answering System," International Journal of Science and Research (IJSR), vol. 3, no. 5, pp. 439-444, 2014.

[2] I. W. O. Granoka et al., Tata Bahasa Baku Bahasa Bali. Denpasar: Balai Penelitian Bahasa Pusat Pembinaan dan Pengembangan Bahasa Departemen Pendidikan dan Kebudayaan, 1996.

[3] J. Prager, J. Chu-Carroll, E. W. Brown, and K. Czuba, "Question Answering By Predictive Annotation," in Advances in Open Domain Question Answering, T.

Strzalkowski and S. M. Harabagiu, Eds. Dordrecht: Springer, 2008, pp. 307-347.

[4] N. Yusliani and A. Purwarianti, "Sistem Question Answering Bahasa Indonesia untuk Pertanyaan Non - Factoid," Jurnal Ilmu Komputer dan Informasi, vol. 4, no. 1, pp. 1014, 2011.

[5] A. Purwarianti, "Developing Cross Language Systems for Language Pair with Limited Resource: Indonesian - Japanese CLIR and CLQA," Toyohashi University of Technology, Japan, 2007.

[6] N. P. Er and I. Cicekli, "A Factoid Question Answering System Using Answer Pattern Matching," in International Joint Conference on Natural Language Processing (IJCNLP), 2013, pp. 854-858.

[7] R. Rosyadi, S. Al-Faraby, and Adiwijaya, "Penerapan Question Answering System Pada Pembahasan Agama Islam Dengan Pendekatan Metode Pattern Based," Jurnal Media Informatika Budidarma, vol. 2, no. 4, pp. 140-149, 2018.

[8] I. P. G. A. Sudiatmika, I. M. A. W. Putra, K. H. S. Dewi, and I. K. B. Aryawan, "Line Bot Implementation for Automation Balinese Language Dictionary," in International Conference on Cybernetics and Intelligent System (ICORIS), 2019, pp. 227-232.

[9] I. B. G. W. Putra, M. Sudarma, and I. N. S. Kumara, "Klasifikasi Teks Bahasa Bali dengan Metode Supervised Learning Naive Bayes Classifier," Teknologi Elektro, vol. 15, no. 2, pp. 81-86, 2016.

[10] M. A. P. Subali and C. Fatichah, "Kombinasi Metode Rule-Based dan N-Gram 
Stemming untuk Mengenali Stemmer Bahasa Bali,” Jurnal Teknologi Informasi dan Ilmu Komputer (JTIIK), vol. 6, no. 2, 2019.

[11] M. A. Fauzi, A. Z. Arifin, and A. Yuniarti, "Term Weighting Berbasis Indeks Buku dan Kelas untuk Perangkingan Dokumen Berbahasa Arab," Lontar Komputer, vol. 5, no. 2, pp. 435-442, 2014.

[12] T. M. Sembok and Z. A. Bakar, "Effectiveness of Stemming and N-Grams String Similarity Matching on Malay Documents," International Journal of Applied Mathematics and Informatics, vol. 5, no. 3, pp. 208-215, 2011.

[13] M. S. HUSAIN, “An Unsupervised Approach to Develop Stemmer," International Journal on Natural Language Computing (IJNLC), vol. 1, no. 2, pp. 15-23, 2012. 